\title{
URBAN-INDUSTRIAL SYMBIOSIS TO SUPPORT SUSTAINABLE ENERGY TRANSITION
}

\author{
MARIA ANGELA BUTTURI \& RITA GAMBERINI \\ Department of Science and Methods for Engineering, University of Modena and Reggio Emilia, Italy.
}

\begin{abstract}
Despite the growing interest in the field of urban-industrial symbiosis as well as in sustainable energy solutions at the city level, a research gap is recognized in terms of analyzing the advantages of energy symbiosis networks between industrial and urban areas integrating renewable energy systems.

The urban-industrial symbiosis can support both urban transition toward sustainability and industrial green innovation through creating advantageous relationships in the framework of a common low-carbon strategy between industrial districts and neighboring urban areas. Urban-industrial symbiosis extends the concept of industrial symbiosis, a part of the industrial ecology field, to urban-industrial synergies. Taking advantage of the geographic proximity, it promotes the exchanges of waste, resources, and energy between urban and industrial areas, as well as the sharing of infrastructure.

Thus, the paper aims at presenting an in-depth analysis of the main urban-industrial symbiosis schemes based on low-carbon energy flows between industries and cities, investigating the energy synergies potential. It introduces the concept and outline of sustainability-driven framework with the aim of modeling urban-industrial energy symbiosis networks integrating renewable energy sources from a multi-stakeholder point of view and supporting decision-making on the economic, environmental, and social sustainability of the energy synergies.

Keywords: low-carbon transition, renewable energy sources, sustainable energy, urban-industrial symbiosis.
\end{abstract}

\section{INTRODUCTION}

Urban areas play an important role in energy consumption and carbon emissions. Cities sustainability strongly depend on their interconnections with the surrounding ecosystem [1]. Moreover, an integrated approach to urban sustainable development should involve the neighboring territory and business areas to guarantee optimized planning strategy and longterm perspective [2]. This integrated approach can be realized through the urban-industrial symbiosis (UIS).

The UIS can be considered as an extension of the industrial symbiosis (IS) that aims at creating advantageous synergies between firms. According to the United Nations Industrial Development Organization, clustering of industries and the creation of eco-industrial parks (EIP) promote the development of urban-industrial synergies and allow to reduce the cost of joint infrastructure [3].

As the IS can bring benefits to the local communities, allowing to save local resources and reducing waste to be managed by the local infrastructure [4, 5], the UIS builds up relationships between cities and local industrial sites that can harmonize the coexistence of living and production areas [6], improving the environmental, social, and economic sustainability of the whole system [2]. The basic concept underpinning the UIS approach is that urban waste can be delivered to nearby industrial clusters for incineration or recycling, while industries can provide back available extra electrical or thermal energy [7].

The contribution of UIS to the circular economy promotion as well as to the reduction of urban and industry environmental impact is widely recognized $[6,8,9]$ and the environmental benefits quantified $[10,11]$. On the other hand, energy solutions integrating 
renewable energy sources (RES) at buildings, at a district or urban level, are considered as an effective way to support the urban transition toward energy sustainability $[12,13]$. Nevertheless, the advantages of energy symbiosis networks between industrial and nearby urban areas that also integrate renewable energy systems are still underinvestigated [14].

Based on this background, this paper focuses on the main UIS approaches involving low-carbon energy links between industries and cities, aiming at investigating the potential of creating RES synergies at urban-industrial level. Starting from the available literature (section 2), the RES potential at an urban level and within UIS projects is discussed (section 3) and a framework for supporting decision-making in UIS projects integrating RES is developed (section 4), driven by the sustainability goals and considering the complexity of the multi-stakeholder involvement.

\section{ENERGY-BASED UIS - AN OVERVIEW}

\subsection{The UIS approach}

The UIS concept arose from existing IS projects to fully exploit the advantages of a collaborative approach in reducing the environmental impact at a local level. Due to fast urban development, urban areas generate an increasing amount of waste and they play an important role in water and energy consumption [15]. Thus, at the basic level, urban waste can be used as a secondary raw material in industrial processes [16] or as an energy source in industrial waste treatment facilities, avoiding the building of new plants, improving existing plants saturation, and reducing waste landfill [9].

Waste flows from cities to industrial sites can be manifold:

- Municipal solid waste can be incinerated for heat recovering and power generation [8, 17] or production of intermediate fuel [16]. It can be delivered for fueling industrial furnaces, mainly in energy-intensive industries such as iron/steel, cement [8], and paper industry [18]. Mixed plastics are used for ammonia production [19] and as a reductant in iron industry, while fly ash can be used in cement industry [20].

- Separately collected materials can be recycled if recycling companies are established within the industrial district (plastics [19], steel [20], glass and electronic waste [19]) or reused as alternative raw materials like plastics in cement or scrap tyres [18, 21].

- Organic waste can be used for energy production (e.g. by anaerobic digestion, pyrolysis, or gasification) [22], sometimes managed by a public multi-utility [17].

- Urban waste water can be collected and treated to be reused in industrial processes (i.e. in iron/steel industry [20]).

- Sewage sludge can be used for energy production [23].

On the other hand, the waste heat resulting from industrial processes can be supplied to urban areas through a district heating model: high- and low-grade heat can serve both residential and commercial buildings (department stores, office buildings, hospitals). This solution is considered an effective way to reduce the environmental impact at local urban level and, considering the need for heat pipelines, the geographic proximity between energy consumers and industrial suppliers is a key factor [24, 25]. Since the infrastructure investment cost can have a long payback time, the implementation 


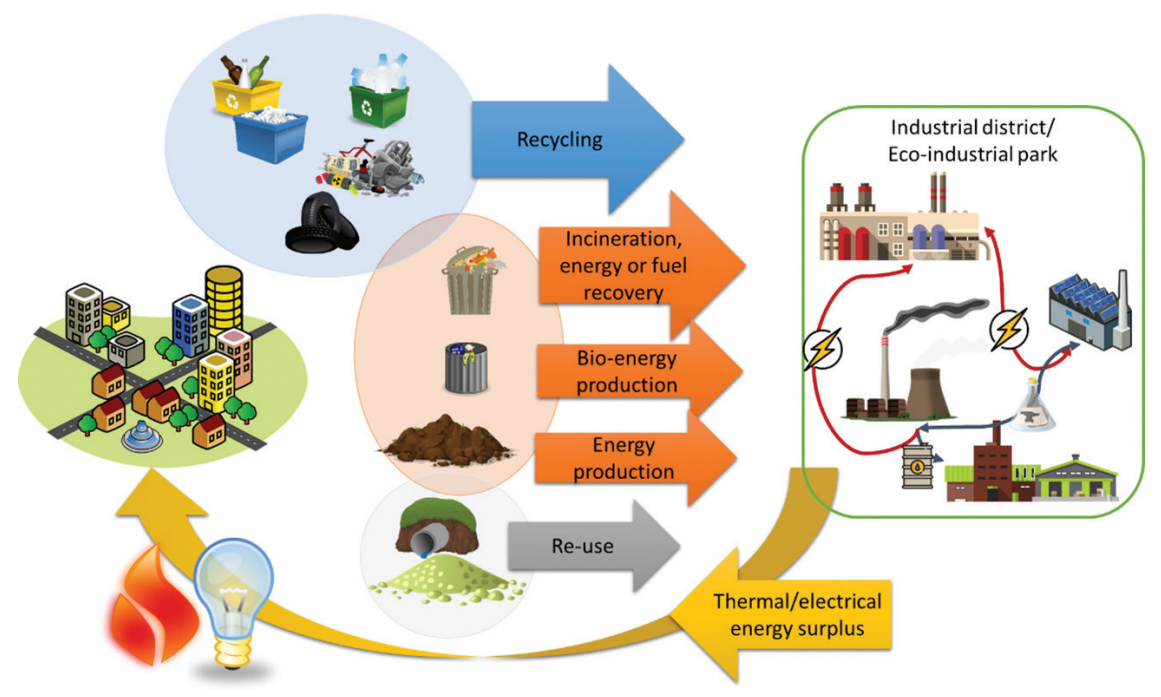

Figure 1: Potential and existing resource exchanges within UIS framework.

strategy should be based on a public-private business model and take into account stakeholders' participation [26]. Since the installation and operation phases of heat management plants are not the main businesses of manufacturing firms, a service company should at least partially finance the project and handle the operation of the district heating grid [27].

Low-grade industrial heat as well as industrial wastewater, mainly produced by pulp and paper and food industry at a temperature range of $35^{\circ} \mathrm{C}-90^{\circ} \mathrm{C}$, can be used for heating/cooling through heat pumps [28].

Figure 1 presents a graphical representation of the overview of urban-industrial synergies.

From the previous literature overview, some materials flowing from the city to the industrial district can be categorized as energy based, since the exchanged materials are converted into energy (orange arrows in the picture). Similarly, heat or electricity surplus can flow form the industrial district to the urban area (yellow arrow in the picture).

\subsection{Energy-based UIS}

The energy-based IS projects involving urban areas available in the literature mainly concern the energy production from urban wastes and the heat recovering from industrial processes or co-generation plants for district heating [29]. Electricity recovery or exchanges are the less-common practices, probably due to the high cost or low maturity level of the storage technologies and the still little diffusion of tools for the demand response management [30]. Storage facilities should also take into account the time shifts between the energy demand in cities and the energy supplying by industry [28]. In Table 1, some common energy-based synergies selected from the literature are presented. 
Table 1: Energy-based synergies at an urban-industrial level.

\begin{tabular}{|c|c|c|c|}
\hline UIS involving energy exchanges & $\begin{array}{l}\text { Energy to } \\
\text { city }\end{array}$ & $\begin{array}{l}\text { Energy to } \\
\text { EIP }\end{array}$ & Source \\
\hline Coal plant/CHP plant & $X$ & & [11] \\
\hline Incineration plant fueled by MSW & & $\mathrm{X}$ & {$[11,17,21,26]$} \\
\hline $\begin{array}{l}\text { Biomass plant fueled by urban } \\
\text { organic waste }\end{array}$ & & $\mathrm{X}$ & {$[11,17,26]$} \\
\hline $\begin{array}{l}\text { Co-generation plant and power } \\
\text { generation }\end{array}$ & $\mathrm{X}$ & & {$[31]$} \\
\hline $\begin{array}{l}\text { Industrial waste heat from indus- } \\
\text { trial processes (DH model) }\end{array}$ & $\mathrm{X}$ & & {$[21,24-26,28,32]$} \\
\hline $\begin{array}{l}\text { On-roof photovoltaic and solar } \\
\text { thermal plants }\end{array}$ & $\mathrm{X}$ & $\mathrm{X}$ & {$[28]$} \\
\hline Wind turbine installation in EIPs & $\mathrm{X}$ & $\mathrm{X}$ & {$[33]$} \\
\hline $\begin{array}{l}\text { Low-grade industrial waste heat } \\
\text { (heat pump-Rankine cycle) }\end{array}$ & $\mathrm{X}$ & & {$[28]$} \\
\hline Wastewater (heat pump) & $X$ & & {$[28]$} \\
\hline
\end{tabular}

CHP, combined heat and power; EIP, eco-industrial parks; MSW, municipal solid waste.

\section{RENEWABLE ENERGY POTENTIAL IN UIS}

\subsection{RES in urban-industrial context}

The reduction of industrial carbon emissions is an urgent issue, especially in densely populated areas, and the decarbonization pathways should involve both more sustainable processes as well as the replacement of fossil fuels with RES [34]. Since cities play an important role in energy consumption and carbon emissions, the neighbor EIP can provide clean energy to local communities, thus improving the social role of industry. When renewable energy plants, such as for wind turbines, raise issues concerning spatial impact, the industrial parks can be the most acceptable places to install them [33]. Moreover, often companies have large empty roof space where photovoltaics (PV) or solar thermal collectors could be installed to provide renewable energy to residential and commercial areas; different business models should be considered involving the company itself (that can both finance and operate the project or rent the roof), an external service company for financing and operating the project, and the citizens that could participate in the project financing [27].

Residential, commercial, and industrial sectors have specific energy consumption patterns, sometimes complementary: as an example, with respect to solar power production peaks, commercial and residential electricity demand is complementary. Urban and industrial energy demand can be satisfied by combining various sources of energy: in analogy with the smart grid concept, a smart energy system approach is suggested by Lund et al. [35] to combine electricity, heat, and gas grids with storage technologies to allow sustainability-oriented synergies among industrial, commercial, and residential sectors. A regional multi-energy scheme, based on energy hubs combining distributed energy supply, RES, and combined heat and power (CHP), is modeled to serve residential, commercial, and industrial districts in [36]. The smart 
technologies allow the creation of smart infrastructures and energy management platforms between smart cities and industrial parks, promoting UIS integrating RES [37]. Thus, the symbiosis strategy acts as a systemic innovation approach, allowing the realization of multi-energy systems with a high renewable energy share and the use of innovative technologies [9]. Within the UIS context, eco-efficiency and eco-innovation are two main advantages of industrial partners, while local communities benefit from environmental restoration and improved wellbeing [16].

Local authorities play a key role in the realization of UIS projects integrating RES. This is strongly pursued by the local authorities through policy actions and subsidies, supporting directly the UIS project, RES installation, or innovation measures and infrastructure [38, 39]. Moreover, they can facilitate other stakeholders' awareness on symbiosis and clean energy advantages and their engagement in the project [40].

\subsection{RES in urban context}

The concept of nearly zero-energy building, introduced by the European Energy Performance of Buildings Directive [41] with the aim of pushing for maximizing energy efficiency and increasing the share of renewable energy at building level, brought along the concepts of nearly zero-energy district (NZED) and residential net zero energy system that apply to intermediate or urban scale $[42,43]$. They consider multi-energy systems to satisfy residential/ commercial and public infrastructure electricity demand, as well as mobility and heating/ cooling energy demand. These energetic systems include renewable energy technologies and storage systems such as electric vehicles to manage the volatility of some RES.

Cities have a great potential for the adoption of RES since they can be integrated in buildings avoiding land use; moreover, thanks to the local power production via distributed generation and energy hubs, the grid transmission losses can be reduced [44]. The renewable technologies that can be considered for their adaptability to urban context are solar (for the availability of surfaces on buildings), bioenergy to produce heat and power, and wind (micro-turbine for micro-generation applications). These technologies should be associated with seasonal storage (e.g. ground- or water-based thermal storage).

Rotterdam local authorities included the adoption of the UIS approach within the energy plan supporting city's climate strategy, recognizing three main steps to be fulfilled: to reduce energy consumption via architecture, to reuse waste energy flows, and to use renewable energy [45]. The integration of RES is planned at the building, neighborhood, district, and central (city) scale, within an integrated framework. A micro-grid model, including solar energy, tri-generation, and storage systems, applied to the city of New York showed that, in order to achieve the set target of $26 \%$ carbon reduction, industrial waste heat and substantial PV electricity should be employed [46].

\section{UIS INTEGRATING RES - A FRAMEWORK}

\subsection{UIS integrating RES architecture}

From the schemes discussed in the previous literature review, renewable energy technologies can be locally adopted at buildings level (residential, industrial - warehouse or office - and commercial), district level, or central level (joint projects between the industrial district and the city). Collective power production and distributed generation resources can allow the integration of a high share of RES. A smart multi-energy grid configuration, controlled 


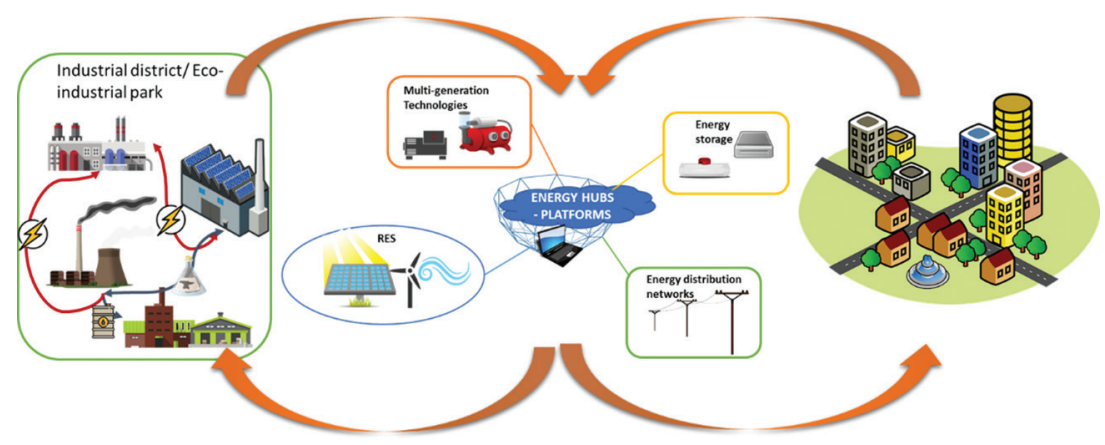

Figure 2: The smart multi-energy grid configuration, supported by information exchange platforms, manages the energy hubs serving the UIS.

according to the energy hub model, can manage the energy exchanges between the city and the industrial park (Fig. 2). The energy hub works essentially as an interface between primary energy sources and end-users, while communication platforms allow an effective exchange of information among actors.

The main renewable energy conversion technologies fitting the UIS projects combine the RES suitable for industrial and residential applications: waste/biomass treatment plants, wind turbines, solar panels (thermal collectors and PV units), ground-source heat pumps. Also, the carbon capture and storage technology, that transforms carbon dioxide emitted in the atmosphere into fuel and other products, is suggested for application in the UIS [47].

\subsection{Critical issues}

Some critical issues must be taken into account when modeling UIS integrating RES. They can be technical, economic, regulatory, or organizational $[29,48]$.

- Multiple stakeholders' involvement: The strong cooperation and knowledge sharing among the involved stakeholders, who must share a strong commitment to the sustainability development goals, is the prerequisite for a UIS project.

- Resource availability: The resource (biomass, solar radiation, or wind) must be locally available to guarantee the economic feasibility.

- Flexibility: A number of flexibility options, such as energy storage systems or the inclusion of electric vehicles, must be considered to increase the whole system reliability by decoupling temporally demand and supply [49].

- Space: The land or building's space availability must be investigated and the general agreement for the installation sites reached; the geographic proximity must be defined.

\subsection{Sustainability aspects}

Sustainability is a key issue of energy projects. The most investigated sustainability aspects of energy-based UIS projects are related to techno-economic feasibility and to the environmental impact [50]. Few authors also consider social benefits [51].

The economic sustainability must allow the energy stakeholders, industries, and local communities to achieve economic growth. The economic feasibility is influenced by the fossil fuel prices and the conventional fuel saving, the cost-effectiveness of installing renewable 
technologies, namely by the renewable technology cost (considering also the operating phase), and the renewable source availability. The intermittence of some RES has also to be taken into account, since it may require additional investments [52]. The cost of network connections must also be considered.

From the environmental point of view, the reduction of carbon emissions is the main criterion considered, as it is the project trigger. The emission of renewable technologies in the operating phase is generally considered null; however, even if RES are conventionally claimed as clean energy, a life cycle-based evaluation can provide a clearer understanding of the environmental impact reduction [52].

The social sustainability pertains to social well-being and progress of the involved community. The social expected benefits of the energy-based UIS projects are jobs creation, energy bills reduction, and improved health due to the reduction of carbon dioxide emissions [53, 54]. Afshari et al. [51] introduce in their multi-objective optimization model a 'social value preference', considering a qualitative parameter representing the values of suppliers perceived by customers according to a set of environmental and social criteria.

\subsection{The multi-stakeholders view}

As previously observed, a main characteristic of the UIS projects is the high complexity due to the involvement of multiple stakeholders. Industrial partners, energy service providers, citizens, and local authorities are the main actors involved in the project, also including academia with the role of enhancing innovation, promoting knowledge sharing, and providing information about the project potential results, supporting the alignment of goals [48].

Stakeholders with different objectives must be kept together by the common low-carbon strategy. The main goal of the industrial partners is profit, and energy-related innovation may not represent a primary concern [55]. On the other hand, communities ask for reducing the industrial environmental impact and, at the same time, creating jobs and reducing the energy bill [55]. Local authorities, starting from the low-carbon strategy, aim at maximizing the economic, environmental, and social advantages of the UIS project.

A collective point of view must be formed (Fig. 3) and analyzed.

On these bases, a multi-objective approach can allow to facilitate the trade-off between conflicting objectives, such as minimization of both costs and carbon emissions [47].

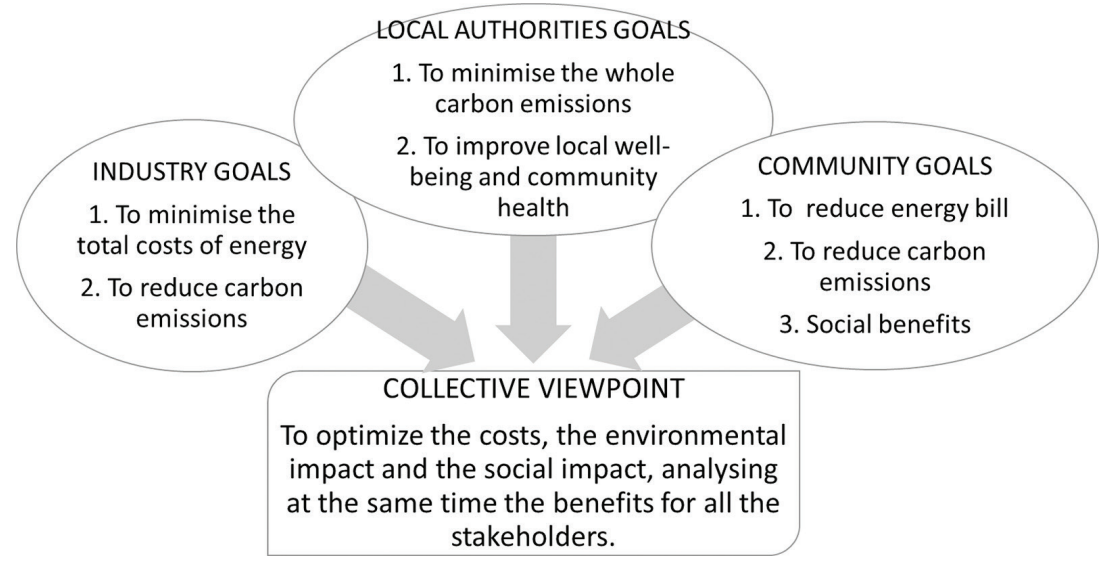

Figure 3: The multi-stakeholder views. 
- Multi-stakeholders engagement

- Electricity demand and stakeholders' expectations analysis

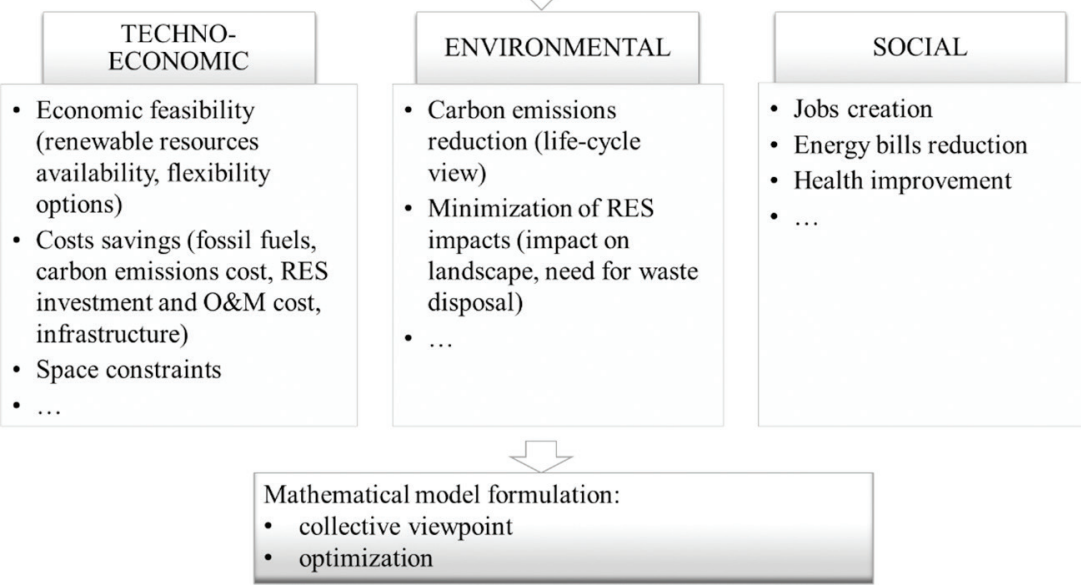

Figure 4: Schematic diagram for the sustainability-driven framework implementation.

4.5 Framework implementation: a pattern example

Based on the outlined framework, an implementation pattern is suggested to designing an UIS project integrating RES (Fig. 4). Some of the main sustainability criteria that should drive an UIS project are shown in the figure.

The implementation pattern is built up considering a historical town located in the North of Italy, surrounded by a territory where modern farms coexist with industrial districts made up of small and medium-sized enterprises. Here, the local authorities are going to introduce an urban regeneration strategy, including the requalification of an industrial district considering urban-industrial potential synergies. The close relationship between the urban community and the productive district facilitates the emergence of a shared commitment to improve the socio-economic urban quality, while reducing the environmental impacts.

A stakeholders' engagement and knowledge sharing phase will promote a strong cooperation among businesses and with the urban community. According to the analysis of stakeholders' needs, the techno-economic, environmental, and social key objectives will constitute the basis for the formulation of a mathematical decision support model.

\section{CONCLUSION}

The UIS integrating renewable energy solutions is a promising approach to pursue a low-carbon strategy. However, this approach is still scarcely investigated and applied.

Starting from the scientific literature available on the topic, this study analyzes the key aspects of developing an UIS project integrating RES. Moreover, it presents a general framework that includes a description of generic technologies and architecture, the main critical factors to consider, the sustainability issues, and the multiple stakeholder views. Lastly, a possible pattern for the framework implementation is suggested, as the developed framework will represent the foundation for the development of a decision support model to be applied to support a local administration which is going to requalify an industrial district close to the urban area. The aim of the model will be to actively involve both companies and urban 
communities in the project, hopefully showing the potential collective advantages of the UIS integrating RES.

\section{REFERENCES}

[1] European Commission, Science for Environment Policy In-depth-report: Indicators for sustainable cities. In-depth Report 12, Vol. 2015, No. 12, p. 24, 2018.

[2] Bian, Y., Dong, L., Liu, Z. \& Zhang, L., A sectoral eco-efficiency analysis on urbanindustrial symbiosis. Sustainability, 12(9), pp. 1-19, 2020. https://doi.org/10.3390/ su12093650

[3] UNIDO, Eco-industrial Parks - Achievements and Key Insights from the Global RECP programme, 2019.

[4] Chertow, M., Gordon, M., Hirsch, P. \& Ramaswami, A., Industrial symbiosis potential and urban infrastructure capacity in Mysuru, India. Environmental Research Letters, 14(7), 075003, 2019. https://doi.org/10.1088/1748-9326/ab20ed

[5] Lolli, F. et al., Waste treatment: an environmental, economic and social analysis with a new group fuzzy PROMETHEE approach. Clean Technologies and Environmental Policy, 18(5), pp. 1317-1332, 2016. https://doi.org/10.1007/s10098-015-1087-6

[6] Dong, L., Liang, H., Zhang, L., Liu, Z., Gao, Z. \& Hu, M., Highlighting regional eco-industrial development: Life cycle benefits of an urban industrial symbiosis and implications in China. Ecological Modelling, 361, pp. 164-176, 2017. https://doi. org/10.1016/j.ecolmodel.2017.07.032

[7] Dong, H., Ohnishi, S., Fujita, T., Geng, Y., Fujii, M. \& Dong, L., Achieving carbon emission reduction through industrial \& urban symbiosis: A case of Kawasaki. Energy, 64, pp. 277-286, 2014. https://doi.org/10.1016/j.energy.2013.11.005

[8] Sun, L., et al., Energy-saving and carbon emission reduction e ff ect of urban-industrial symbiosis implementation with feasibility analysis in the city. Technological Forecasting and Social Change, 151, 119853, 2020. https://doi.org/10.1016/j.techfore.2019.119853

[9] Fujii, M., et al., Possibility of developing low-carbon industries through urban symbiosis in Asian cities. Journal of Cleaner Production, 114, pp. 376-386, 2016. https://doi. org/10.1016/j.jclepro.2015.04.027

[10] Ohnishi, S., Dong, H., Geng, Y., Fujii, M. \& Fujita, T., A comprehensive evaluation on industrial \& urban symbiosis by combining MFA, carbon footprint and emergy methods-Case of Kawasaki, Japan. Ecological Indicators, 73, pp. 315-324, 2017. https:// doi.org/10.1016/j.ecolind.2016.10.016

[11] Lu, C., Wang, S., Wang, K., Gao, Y. \& Zhang, R., Uncovering the benefits of integrating industrial symbiosis and urban symbiosis targeting a resource-dependent city: A case study of Yongcheng, China. Journal of Cleaner Production, 255, 120210, 2020. https:// doi.org/10.1016/j.jclepro.2020.120210

[12] Zhang, X., et al., A review of urban energy systems at building cluster level incorporating renewable-energy-source (RES) envelope solutions. Applied Energy, 230, pp. 1034-1056, 2018. https://doi.org/10.1016/j.apenergy.2018.09.041

[13] Manfren, M., Caputo, P. \& Costa, G., Paradigm shift in urban energy systems through distributed generation: Methods and models. Applied Energy, 88(4), pp. 1032-1048, 2011. https://doi.org/10.1016/j.apenergy.2010.10.018

[14] Butturi, M.A., Lolli, F., Sellitto, M.A., Balugani, E., Gamberini, R. \& Rimini, B., Renewable energy in eco-industrial parks and urban-industrial symbiosis: A literature 
review and a conceptual synthesis. Applied Energy, 255, 113825, 2019. https://doi. org/10.1016/j.apenergy.2019.113825

[15] García-guaita, F., González-garcía, S., Villanueva-rey, P., Teresa, M. and Feijoo, G., Integrating urban metabolism, material flow analysis and life cycle assessment in the environmental evaluation of Santiago de Compostela. Sustainable Cities and Society, 40, pp. 569-580, 2018. https://doi.org/10.1016/j.scs.2018.04.027

[16] Van Berkel, R., Fujita, T., Hashimoto, S. \& Geng, Y., Industrial and urban symbiosis in Japan: Analysis of the Eco-Town program 1997-2006. Journal of Environmental Management, 90(3), pp. 1544-1556, 2009. https://doi.org/10.1016/j.jenvman.2008.11.010

[17] Marchi, B., Zanoni, S. \& Zavanella, L.E., Symbiosis between industrial systems, utilities and public service facilities for boosting energy and resource efficiency. Energy Procedia, 128, pp. 544-550, 2017. https://doi.org/10.1016/j.egypro.2017.09.006

[18] Dong, L., Gu, F., Fujita, T., Hayashi, Y. \& Gao, J., Uncovering opportunity of low-carbon city promotion with industrial system innovation: Case study on industrial symbiosis projects in China. Energy Policy, 65, pp. 388-397, 2014. https://doi.org/10.1016/j. enpol.2013.10.019

[19] Van Berkel, R., Fujita, T., Hashimoto, S. and Fujii, M., Quantitative assessment of urban and industrial symbiosis in Kawasaki, Japan. Environmental Science and Technology, 43(5), pp. 1271-1281, 2009. https://doi.org/10.1021/es803319r

[20] Dong, L., et al., Environmental and economic gains of industrial symbiosis for Chinese iron/steel industry: Kawasaki's experience and practice in Liuzhou and Jinan. Journal of Cleaner Production, 59, pp. 226-238, 2013. https://doi.org/10.1016/j. jclepro.2013.06.048

[21] Fang, K., Dong, L., Ren, J., Zhang, Q., Han, L. and Fu, H., Carbon footprints of urban transition: Tracking circular economy promotions in Guiyang, China. Ecological Modelling, 365, pp. 30-44, 2017. https://doi.org/10.1016/j.ecolmodel.2017.09.024

[22] Albino, V., Fraccascia, L. \& Savino, T., Industrial symbiosis for a sustainable city: Technical, economical and organizational issues. Procedia Engineering, 118, pp. 950-957, 2015. https://doi.org/10.1016/j.proeng.2015.08.536

[23] Sokka, L., Pakarinen, S. and Melanen, M., Industrial symbiosis contributing to more sustainable energy use - An example from the forest industry in Kymenlaakso, Finland. Journal of Cleaner Production, 19(4), pp. 285-293, 2011. https://doi.org/10.1016/j. jclepro.2009.08.014

[24] Togawa, T., Fujita, T., Dong, L., Fujii, M. \& Ooba, M., Feasibility assessment of the use of power plant-sourced waste heat for plant factory heating considering spatial configuration. Journal of Cleaner Production, 81, pp. 60-69, 2014. https://doi.org/10.1016/j. jclepro.2014.06.010

[25] Fang, H., Xia, J., Zhu, K., Su, Y. \& Jiang, Y., Industrial waste heat utilization for low temperature district heating. Energy Policy, 62, pp. 236-246, 2013. https://doi. org/10.1016/j.enpol.2013.06.104

[26] Kim, H.W., Dong, L., Choi, A.E.S., Fujii, M., Fujita, T. \& Park, H.S., Co-benefit potential of industrial and urban symbiosis using waste heat from industrial park in Ulsan, Korea. Resources, Conservation and Recycling, 135, pp. 225-234, 2018. https://doi. org/10.1016/j.resconrec.2017.09.027

[27] Karner, K., Theissing, M. \& Kienberger, T., Modeling of energy efficiency increase of urban areas through synergies with industries. Energy, 136, pp. 201-209, 2017. https:// doi.org/10.1016/j.energy.2015.12.139 
[28] Karner, K., Theissing, M. \& Kienberger, T., Energy efficiency for industries through synergies with urban areas. Journal of Cleaner Production, 119, pp. 167-177, 2016. https://doi.org/10.1016/j.jclepro.2016.02.010

[29] Fraccascia, L., Industrial symbiosis and urban areas: A systematic literature review and future research directions. Procedia Environmental Science, Engineering and Management, 5(2), pp. 73-83, 2018.

[30] Holgado, M., Benedetti, M., Evans, S. \& Introna, V., Contextualisation in industrial energy symbiosis: Design process for a knowledge repository. XXI Summer School "Francesco Turco", pp. 139-144, 2016.

[31] Dong, L., et al., Towards preventative eco-industrial development: An industrial and urban symbiosis case in one typical industrial city in China. Journal of Cleaner Production, 114, pp. 387-400, 2016. https://doi.org/10.1016/j.jclepro.2015.05.015

[32] Afshari, H., Jaber, M.Y. \& Searcy, C., Extending industrial symbiosis to residential buildings: A mathematical model and case study. Journal of Cleaner Production, 183, pp. 370-379, 2018. https://doi.org/10.1016/j.jclepro.2018.02.148

[33] Maes, T., et al., Energy management on industrial parks in Flanders. Renewable and Sustainable Energy Reviews, 15(4), pp. 1988-2005, 2011. https://doi.org/10.1016/j. rser.2010.11.053

[34] UNIDO, Industrial Development Report 2018. Demand for Manufacturing: Driving Inclusive and Sustainable Industrial Development, Vienna, 2017.

[35] Lund, H., Alberg, P., Connolly, D. \& Vad, B., Smart energy and smart energy systems. Energy, 137, pp. 556-565, 2017. https://doi.org/10.1016/j.energy.2017.05.123

[36] Yang, H., Xiong, T., Qiu, J., Qiu, D. and Dong, Z.Y., Optimal operation of DES/CCHP based regional multi-energy prosumer with demand response. Applied Energy, 167, pp. 353-365, 2016. https://doi.org/10.1016/j.apenergy.2015.11.022

[37] Wang, Y., Ren, H., Dong, L., Park, H.-S., Zhang, Y. and Xu, Y., Smart solutions shape for sustainable low-carbon future: A review on smart cities and industrial parks in China. Technological Forecasting Social and Change, 144, pp. 103-117, 2019. https:// doi.org/10.1016/j.techfore.2019.04.014

[38] Fraccascia, L., The impact of technical and economic disruptions in industrial symbiosis relationships: An enterprise input-output approach. International Journal of Production Economics, 213, pp. 161-174, 2019. https://doi.org/10.1016/j.ijpe.2019.03.020

[39] Yu, F., Han, F. and Cui, Z., Reducing carbon emissions through industrial symbiosis: A case study of a large enterprise group in China. Journal of Cleaner Production, 103, pp. 811-818, 2015. https://doi.org/10.1016/j.jclepro.2014.05.038

[40] Tao, Y., Evans, S., Wen, Z. \& Ma, M., The influence of policy on industrial symbiosis from the Firm's perspective: A framework. Journal of Cleaner Production, 213, pp. 1172-1187, 2019. https://doi.org/10.1016/j.jclepro.2018.12.176

[41] European Parliament and Council, Directive 2010/31/EU, Official Journal of the European Union, 2010.

[42] Amaral, A.R., Rodrigues, E., Rodrigues Gaspar, A. \& Gomes, Á., Review on performance aspects of nearly zero-energy districts. Sustainable Cities and Society, 43, pp. 406-420, 2018. https://doi.org/10.1016/j.scs.2018.08.039

[43] Lombardi, P., Sokolnikova, P., Arendarski, B., Franke, R., Hoepfner, A. \& Komarnicki, P., Multi-criteria planning tool for a net zero energy village. Proc. - 2018 IEEE Int. Conf. on Environment and Electrical Engineering, 2018 IEEE Industrial and Commercial Power Systems Europe, pp. 1-6, 2018. 
[44] Allegrini, J., Orehounig, K., Mavromatidis, G., Ruesch, F., Dorer, V. \& Evins, R., A review of modelling approaches and tools for the simulation of district-scale energy systems. Renewable and Sustainable Energy Reviews, 52, pp. 1391-1404, 2015. https:// doi.org/10.1016/j.rser.2015.07.123

[45] Lenhart, J., Van Vliet, B. \& Mol, A.P.J., New roles for local authorities in a time of climate change: The Rotterdam Energy Approach and Planning as a case of urban symbiosis. Journal of Cleaner Production, 107, pp. 593-601, 2015. https://doi.org/10.1016/j. jclepro.2015.05.026

[46] Chan, D., Cameron, M. \& Yoon, Y., Key success factors for global application of micro energy grid model. Sustainable Cities and Society, 28, pp. 209-224, 2017. https://doi. org/10.1016/j.scs.2016.08.030

[47] Neves, A., Godina, R., Azevedo, S.G. \& Matias, J.C.O., Carbon dioxide recovery through industrial and urban symbiosis. ICITM 2020, 9th Int. Conf. on Industrial Technology and Management, pp. 171-175, 2020.

[48] Kurdve, M., Jönsson, C. \& Granzell, A.S., Development of the urban and industrial symbiosis in western Mälardalen. Procedia CIRP, 73, pp. 96-101, 2018. https://doi. org/10.1016/j.procir.2018.03.321

[49] Baumann, M., Weil, M., Peters, J.F., Chibeles-Martins, N. \& Moniz, A.B., A review of multi-criteria decision making approaches for evaluating energy storage systems for grid applications," Renewable and Sustainable Energy Reviews, 107, pp. 516-534, 2019. https://doi.org/10.1016/j.rser.2019.02.016

[50] Butturi, B., Lolli, M.A., Balugani, F., Gamberini, E. \& Rimini, R., Distributed renewable energy generation: A critical review based on the three pillars of sustainability. Proc. Summer School “Francisco Turco”, Sept. 2018, pp. 179-185, 2018.

[51] Afshari, H., Tosarkani, B.M., Jaber, M.Y. \& Searcy, C., The effect of environmental and social value objectives on optimal design in industrial energy symbiosis: A multi-objective approach. Resources, Conservation and Recycling, 158, 104825, 2020. https://doi. org/10.1016/j.resconrec.2020.104825

[52] Liew, P.Y., et al., Total site heat integration planning and design for industrial, urban and renewable systems. Renewable and Sustainable Energy Reviews, 68, pp. 964-985, 2017. https://doi.org/10.1016/j.rser.2016.05.086

[53] Reuter, M., Patel, M.K., Eichhammer, W., Lapillonne, B. \& Pollier, K., A comprehensive indicator set for measuring multiple benefits of energy efficiency. Energy Policy, 139, 111284, 2020. https://doi.org/10.1016/j.enpol.2020.111284

[54] Sierra, L.A., Yepes, V. \& Pellicer, E., A review of multi-criteria assessment of the social sustainability of infrastructures. Journal of Cleaner Production, 187, pp. 496-513, 2018. https://doi.org/10.1016/j.jclepro.2018.03.022

[55] Timmerman, J., Vandevelde, L. \& Van Eetvelde, G., Towards low carbon business park energy systems: Classification of techno-economic energy models. Energy, 75, pp. 68-80, 2014. https://doi.org/10.1016/j.energy.2014.05.092 